\title{
Where the Ends Meet: An Overview of Sex Determination in Atheriniform Fishes
}

\author{
Carlos A. Strüssmann ${ }^{a}$ Yoji Yamamoto ${ }^{a}$ Ricardo S. Hattori ${ }^{\mathrm{a}}$ \\ Juan I. Fernandino ${ }^{b}$ Gustavo M. Somozab \\ aGraduate School of Marine Science and Technology, Tokyo University of Marine Science and Technology, Tokyo, \\ Japan; 'bnstituto Tecnológico de Chascomús (CONICET-UNSAM), Chascomús, Argentina
}

\section{Keywords}

Atheriniformes · Genotypic sex determination · Sex determination $\cdot$ Sex differentiation - Temperaturedependent sex determination

\begin{abstract}
Atheriniform fishes have recently emerged as attractive models for evolutionary, ecological, and molecular/physiological studies on sex determination. Many species in this group have marked temperature-dependent sex determination (TSD) and yet many species also have a sex determinant gene that provides a strong drive for male differentiation. Thus, in these species the 2 forms of sex determination that were once considered to be mutually exclusive, environmental (ESD) and genotypic (GSD) sex determination, can coexist at environmentally relevant conditions. Here, we review the current knowledge on sex determination in atheriniform fishes with emphasis on the molecular and physiological mechanisms of ESD and GSD, the coexistence and cross-talk between these 2 mechanisms, the possibility of extragonadal transduction of environmental information and/or extragonadal onset of sex determination, and the results of field studies applying novel tools such as otolith in-
\end{abstract}

karger@karger.com www.karger.com/sxd

(C) 2021 S. Karger AG, Basel

Karger crement analysis and molecular markers of genetic sex developed for selected New World and Old World atheriniform species. We also discuss the existence of molecular and histological mechanisms to prevent the discrepant differentiation in parts of the gonads because of ambiguous or conflicting environmental and genetic signals and particularly the possibility that the female is the default state in these species.

(c) 2021 S. Karger AG, Basel

Atheriniform fishes are globally distributed in coastal marine, estuarine, and inland water environments and are often referred to as "silversides" [Nelson et al., 2016]. With the exception of some New World species, which can achieve relatively large body sizes and are the subject of commercial and recreational fisheries as well as of aquaculture (particularly the family Atherinopsidae), and some Old World species, which are attractive and prized aquarium fish (e.g., family Melanotaeniidae), representants of this order are generally small and mostly inconspicuous fish whose main importance is as forage for higher trophic level species. Species from this group have recently emerged as attractive models for evolutionary, 
ecological, and molecular/physiological studies on sex determination [Conover, 2004; Blázquez and Somoza, 2010; Fernandino et al., 2013; Hattori et al., 2019, 2020; Yamamoto et al., 2019]. Many species in this group have marked temperature-dependent sex determination (TSD), and yet many species also have a clearly functional genotypic male sex determinant. In addition, non-thermal environmental effects on sex determination have also been demonstrated, such as light conditions, rearing density, and salinity. Thus, in these species the 2 forms of sex determination that were once considered to be mutually exclusive, environmental (ESD) and genotypic (GSD) sex determination, can coexist at environmentally relevant conditions. This coexistence opens the possibility of scrutinizing the analogies, differences, and interactions of both systems to determine gonadal fate and shedding light on the evolution of sex determination in vertebrates in general and poikilotherms in particular. Also, because so many species exhibit TSD, atheriniform fishes may be particularly vulnerable to populational decline or even extinction among fishes amidst the ongoing trend in global warming and climate change [Ospina-Âlvarez and Piferrer, 2008; Strüssmann et al., 2010; Geffroy and Wedekind, 2020]. This constitutes another compelling reason to study sex determination in this group of fishes in addition to advancing basic biological knowledge and biotechnological applications such as the use for sex control in fish farming. Here, we review the current knowledge on sex determination research in atheriniform fishes with emphasis on the molecular and physiological mechanisms of environmental and genetic sex determination, the coexistence and cross-talk between these 2 mechanisms on the possibility of extragonadal transduction of environmental information and/or extragonadal onset of sex determination, and the results of field studies applying molecular markers of genetic sex developed for selected New World and Old World atheriniform species.

\section{Common and Elusive Aspects of Sex Determination and Gonadal Sex Differentiation in Atheriniformes}

Atheriniform fishes rose to prominence in the context of reproductive biology in the early 1980s with the first discovery of TSD, a form of ESD, among fish [Conover and Kynard, 1981]. Until then, ESD, and particularly TSD, were largely thought to be exclusive to reptiles among vertebrates. In a series of elegant studies, however, Conover and colleagues not only demonstrated that in the Atlantic silverside Menidia menidia the sex of an in- dividual is determined by the temperature it experiences early in development [Conover and Fleisher, 1986] but also advanced many evolutionary and ecological concepts of relevance such as the adaptive nature and driving forces for the evolution of ESD/TSD [Conover, 1984, 1992; Conover and Heins, 1987a] and the interactions of genotype and environment on sex determination [Conover and Kynard, 1981; Conover and Heins, 1987b; Conover et al., 1992; Lagomarsino and Conover, 1993] among others. The breakthrough findings for M. menidia soon led to the search and discovery of TSD in a congener from North America, the tidewater silverside M. peninsulae [Middaugh and Hemmer, 1987], and notably also in large-sized South American species of the genus Odontesthes that at that time were being screened as potential candidates for aquaculture [Strüssmann et al., 1996a, 1996b, 1997]. TSD was subsequently demonstrated or suggested also in 3 other New World atheriniforms, the California grunion Leuresthes tenuis [Brown et al., 2014], the pike silverside Chirostoma estor [Corona-Herrera et al., 2016] from central Mexico, and another Menidia species, the inland silverside M. beryllina [DeCourten and Brander, 2017]. More recently and for the first time, TSD was also demonstrated in an Old World species (family Atherinidae), the cobaltcap silverside Hypoatherina tsurugae from the Japanese coasts [Miyoshi et al., 2020]. It must be noted that Atherinidae and Atherinopsidae, where ESD was first detected, are currently considered as relatively distant families within Atheriniformes [Campanella et al., 2015].

In all the above-mentioned species, low and high temperatures favor feminization and masculinization, respectively [see reviews in Strüssmann and Patiño, 1995, 1999; Conover, 2004; Yamamoto et al., 2019]. Thus, TSD and its pattern of expression seems to be widespread among atheriniforms, suggesting that it (or ESD) emerged at the beginning of atheriniform radiation [Strüssmann and Patiño, 1995, 1999; Strüssmann et al., 1996b]. However, there are currently more questions than answers regarding the evolutionary reasons driving the existence of TSD among atheriniforms. The adaptive nature of TSD in $M$. menidia was elegantly demonstrated in a series of studies that associated this trait with differential birth phenology and fitness of males and females. Atlantic silversides are annual (short-lived), semelparous fish, and hence fitness (fecundity) would be enhanced by production of females rather than males early in the spawning season in a process driven by low temperatures [Conover, 1984]. This is because early birth would confer females with more opportunities for growth before reproduction 


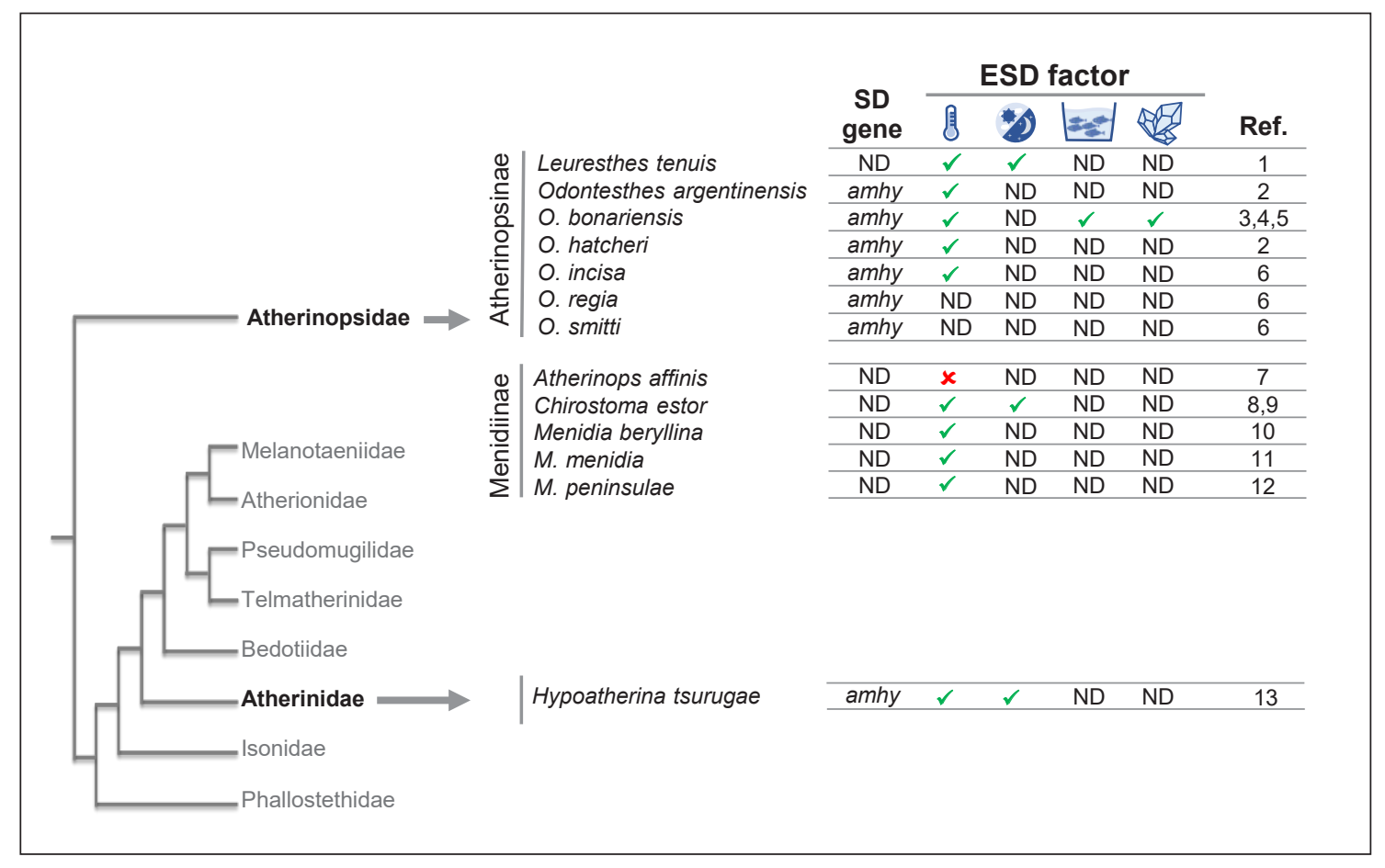

Fig. 1. Mechanisms of sex determination in atheriniform species in relation to the phylogenetic relationships proposed by Campanella et al. [2015]. The presence of a sex-determining (SD) gene and the type of environmental sex determination (ESD) are noted for the various families. The size of branches does not represent divergence time between taxonomic groups. Only species for which studies on sex determination were conducted are included. The types of ESD represented are from left to right water temperature,

and death than males. However, unlike Menidia species, all other atheriniform species in which TSD has been demonstrated are long-lived species that would not accrue the fitness benefits in the context proposed for $\mathrm{Me}$ nidia. Interestingly, recent studies have demonstrated alternative forms of ESD in several atheriniforms with TSD like photoperiod effects in C. estor [Corona-Herrera et al., 2018], L. tenuis [Brown et al., 2014], and likely in H. tsurugae, too [Miyoshi et al., 2020], as well as density [García-Cruz et al., 2020] and salinity [García-Cruz et al., unpubl. results] effects in the pejerrey Odontesthes bonariensis (Fig. 1). Preliminary results for the most extensively studied of these species, O. bonariensis, point to the fact that these other forms of ESD basically involve the same physiological process underlying TSD, i.e., a stress response involving the release of cortisol (see details in the following section) [Hattori et al., 2009, 2020; Fernandino et al., 2012, 2013; García-Cruz et al., 2020, and unpubl. results]. In a broad sense, this could be a fur- photoperiod, rearing density, and salinity. ND, not determined. References: 1) Brown et al. [2014]; 2) Strüssmann et al. [1996b]; 3) Strüssmann et al. [1996a]; 4) García-Cruz et al. [2020]; 5) GarcíaCruz et al., unpubl. results; 6) Hattori et al. [2019]; 7) Baumann et al. [2012]; 8) Corona-Herrera et al. [2016]; 9) Corona-Herrera et al. [2018]; 10) DeCourten and Brander [2017]; 11) Conover and Fleisher [1986]; 12) Middaugh and Hemmer [1987]; 13) Miyoshi et al. [2020].

ther indication that TSD might not be necessarily adaptive in extant species but rather just another facet of an unrelated and poorly regulated physiological process. If this assumption is correct, the presence of TSD in so many atheriniforms may simply reflect a vestigial trait that in long-lived extant species is either adaptively neutral or rendered "harmless", for example by longevity [Bull and Bulmer, 1989; Strüssmann et al., 1996b; Strüssmann and Patiño, 1999; see further discussion in Janzen and Phillips, 2006; see also Baumann et al., 2012 for the case of Atherinops affinis, a longevous atheriniform that apparently does not have TSD].

Regardless of the presumptive mode of sex determination (GSD, ESD, or their interaction), atheriniforms are differentiated gonochorists where the gonads develop directly from an undifferentiated primordium into a testis or ovary without intervening transexual or hermaphroditic stages [Conover and Fleisher, 1986; Strüssmann et al., 1996c; Ito et al., 2005; Strüssmann and Ito, 2005].
Strüssmann/Yamamoto/Hattori/ Fernandino/Somoza 
Likewise, hermaphroditic individuals are extremely rare and, to the best of our knowledge, natural sex reversal like protogynous or protandrous hermaphroditism has never been reported in this group. The onset of ovarian differentiation is usually recognized earlier and at a smaller body size than testicular differentiation by one or more indicators such as marked germ cell proliferation, their entry in meiosis, or the presence of stromal cell aggregations in the dorsal and ventral edges of the gonad that signal the beginning of the formation of the ovarian cavity [Strüssmann et al., 1996b, 1996c]. In O. bonariensis, ovarian and testicular differentiation does not occur simultaneously in all areas of the gonad but follow a characteristic cephalocaudal, left-to-right gradient that hypothetically establishes a hierarchy during differentiation and helps in preventing discrepant differentiation of female and male areas along the gonads [Strüssmann and Ito, 2005]. The critical period of sex determination (CPSD), when the gonads are responsive to both genetic and environmental factors and irreversibly commit to a male or female pathway, has been investigated in M. menidia [Conover and Fleisher, 1986] and O. bonariensis [Strüssmann et al., 1996a, 1997; Ito et al., 2005]. In both species, the CPSD lies during early development, generally a few weeks after hatching, and like other developmental processes is advanced and delayed by high and low temperatures, respectively. Although our knowledge on the mechanisms of genotypic and environmental sex determination in atheriniforms has grown exponentially over the last 2 decades, many questions remain unanswered. For example, 2 intriguing aspects of sex differentiation in atheriniforms are (a) whether feminization of male genotypes (at low temperatures) and masculinization of female genotypes (at high temperatures) involve the same or different mechanisms and (b) how gonads of such ESD species can faithfully develop as ovaries or testes. In addition to clarifying the molecular and physiological processes involved in sex determination of atheriniforms, our group has explored in parallel 3 non-mutually exclusive scenarios that could also explain the paradoxical combination of environmentally labile sex determination with faithful gonadal sex differentiation. These scenarios (or hypotheses) are (a) the early extragonadal (central nervous system or else) differentiation and subsequent imprinting onto the gonads, (b) the existence of a molecular and histological gradient of sex differentiation along different areas of the gonads, and (c) female as the "default sex". These issues are dealt within the following sections that discuss our major findings on sex determination in atheriniforms.

Sex Determination in Atheriniform Fishes

\section{Gonadal Mechanisms of Genetic and Environmental Sex Determination and Differentiation}

The earliest mechanistic exploration of TSD in atheriniforms focused on the involvement of the steroidogenic enzyme aromatase of gonadal origin, following similar studies in reptiles and amphibia. Because this enzyme is central for the balance of feminizing and masculinizing steroids, it was surmised that it could provide a simple explanation for the opposite trends (e.g., masculinization and feminization) at extreme temperatures [Karube et al., 2007; Fernandino et al., 2008a, 2008b; Duffy et al., 2010]. In addition to gonadal cytochrome $\mathrm{P} 450$ aromatase (cyp19a1a), other key genes were also found to be involved in this process, like $d m r t 1$ (doublesex maleabnormal-3 related transcription factor-1) and $a m h$ (anti-Müllerian hormone), and many more have been tentatively implicated but not yet scrutinized [Fernandino et al., 2008a, 2008b, 2010]. In parallel, other studies demonstrated that masculinization induced by high temperatures was associated with gonadal apoptosis in specific areas of the gonads [Yamamoto et al., 2013]. A major breakthrough in understanding the regulation of these processes and of gene expression in general during gonadal sex determination and differentiation arrived with the discovery of the link between the stress hormone cortisol and masculinization in $O$. bonariensis that started with the casual observation that fish at high temperatures seemed stressed. Subsequently, pharmacological and high temperatureinduced elevation of cortisol were shown to inhibit the expression of cyp19ala, increase that of amh, and promote gonadal apoptosis, resulting in higher rates of masculinization at an otherwise sexually neutral (intermediate) temperature [Hattori et al., 2009]. These findings were later corroborated in several other species [Hayashi et al., 2010; Yamaguchi et al., 2010; Mankiewicz et al., 2013; Ribas et al., 2017; Sun et al., 2018; Wang et al., 2019]. In $O$. bonariensis as in other species, cortisol action is mediated by the steroidogenic enzyme 11- $\beta$-hydroxysteroid dehydrogenase-type 2 , encoded by the $h s d 11 b 2$ gene. This enzyme converts 11- $\beta$-hydroxytestosterone to 11 -ketotestosterone, a potent androgen in fish, as an unrelated byproduct of its main function, which is to inactivate cortisol to cortisone [Fernandino et al., 2012, 2013]. Not surprisingly, a cortisol-mediated stress response has been recently implicated also in masculinization by other environmental cues such as crowding stress [García-Cruz et al., 2020], as already suggested by Fernandino et al. [2013]. The fact that cortisol-triggered androgen synthesis is the main driver of stress-related masculinization 
(which seems to be also the case in medaka) [CastañedaCortés et al., 2019, 2020] does not invalidate the possibility that cortisol could also have additional direct agonistic or antagonistic actions on the expression of other sex differentiation genes or cellular processes like apoptosis. These possibilities still need to be scrutinized in atheriniforms.

Another milestone in understanding the process of sex determination in Atheriniformes, the finding of a genotypic determinant of sex in some species, was born out of earlier observations of large inter- and intra-family variation in sex ratios and temperature responsiveness suggestive of a genotypic control [Conover and Kynard, 1981; Conover et al., 1992; Lagomarsino and Conover, 1993; Strüssmann et al., 1996b, 1997; Hattori et al., 2009]. Basic research that started from the development of a sexlinked SNP marker [Koshimizu et al., 2010], the establishment of a strain faithfully inheriting this marker, and the confirmation of the XX-XY system [Hattori et al., 2010] in the Patagonian pejerrey $O$. hatcheri culminated in the discovery of the master sex-determining gene in this species [Hattori et al., 2012]. This gene is a duplication of the autosomal amh ( $a m h a$ ) that is present only on the Y chromosome and therefore was named amhy. Orthologues of amhy were later found in O. bonariensis [Yamamoto et al., 2014] and other species of Odontesthes [Hattori et al., 2019]. More recently, amhy was also found in $H$. tsurugae, an Old World silverside, which, as mentioned earlier, is considered phylogenetically farther removed from Odontesthes within Atheriniformes [Bej et al., 2017]. Curiously, amhy of $H$. tsurugae has a conserved TGF- $\beta$ domain but is devoid of exons 2 and 3 . In these 3 species, high expression of amhy (in XY fish) during the presumed CPSD at intermediate temperatures is highly correlated with male differentiation, in accordance with GSD [Hattori et al., 2012; Yamamoto et al., 2014; Bej et al., 2017]. Interestingly, putative males of $O$. bonariensis show amha upregulation by mid-CPSD when amhy begins to be downregulated, a pattern that differs completely from XY individuals of the other 2 species where amha expression remains low throughout the entire period. In contrast, $\mathrm{XX}$ O. bonariensis presumably developing as females had virtually no detectable amha expression during the CPSD [Yamamoto et al., 2014]. The relative importance of $a m h y$ and $a m h a$ for TSD, on the other hand, has been examined in detail only for the most thermosensitive species of the 3 species, O. bonariensis. Not surprisingly, the results showed that amhy expression was unaffected by temperature whereas that of amha was up- and downregulated at high (masculinizing) and low (feminizing) tempera- tures, respectively [Zhang et al., 2018]. In conclusion, in what appears to be a difference compared to the less thermosensitive (yet also thermolabile) $O$. hatcheri and $H$. tsurugae, the behavior of the autosomal amha in O. bonariensis seems to hold a key role in sex determination in this species. In other words, its expression profile seems to be central to the expression of GSD in XY animals as well as its overriding by high temperature during TSD in XX animals [Zhang et al., 2018].

A common aspect of Amhy and cortisol is that both promote the male pathway. On the other hand, the spatio-temporal expression analysis of cyp19a1a in O. bonariensis clearly confirmed the initial presence of transcripts in both XX and XY gonads. These signals persisted only in animals with low or negligible amh expression (mostly XX animals) and disappeared in those with abundant amh expression (mostly XY fish) [Sarida et al., 2019; unpubl. results]. These lines of evidence support the notion first advanced by Strüssmann and Ito [2005] that in this species the female is the default sex, i.e., that male activators (Amhy, a stressor, or both) have to tip the balance toward testicular development before the irreversible commitment toward an ovary. This represents an attractive, more parsimonious hypothesis that could help to explain feminization at low temperatures as well as masculinization at high temperatures with a single mechanism. Additional support for the female default hypothesis in this species is borne by the histological gradient of sex differentiation previously mentioned [Strüssmann and Ito, 2005], by the observation that apoptosis during gonadal sex differentiation is largely confined to putative males (both at sexually neutral- and masculinizing conditions) [Yamamoto et al., 2013], and more importantly, by a seemingly underlying molecular gradient involving apoptosis, cyp19ala, and amh [Sarida et al., 2019]. Whether this is particular to Atheriniformes or to fish in general remains to be clarified. Evidence for other species seem to indicate a similar overall picture although with species-specific differences in the dependence on $c y$ p19a1a expression and synthesis of estrogens after fertilization. For example, early ovarian differentiation proceeded normally in cyp19a1a-knockout medaka Oryzias latipes [Nakamoto et al., 2018], whereas in cyp19a1aknockout zebrafish Danio rerio all gonads differentiated as testis [Yin et al., 2017]. Although with different results, these examples are also in line with the idea of a mutually controlled antagonism, whereby female or male commitment in the form of gonochorism relies on the timely and sustained expression of key genes for the maintenance of one sex and suppression of the opposite
Sex Dev 2021;15:80-92 DOI: $10.1159 / 00051519$
Strüssmann/Yamamoto/Hattori/ Fernandino/Somoza 
sex as a means to avoid the eventual formation of sexually ambiguous gonads [Warr and Greenfield, 2012; Hattori et al., 2020].

\section{Participation of Extragonadal Tissues in Transduction of Environmental Information and Sex Determination}

A long-standing issue in sex determination and gonadal sex differentiation in vertebrates is where it originates, whether in the gonads or in extragonadal tissues, and atheriniforms are no exception. As regards animals with ESD, the notion that environmental conditions regulate sex differentiation by acting directly on the gonads was first established from studies in reptiles with TSD [Moreno-Mendoza et al., 2001; Pieau and Dorizzi, 2004]. Although never clearly specified, this was the assumed concept in fish, and for this reason, most of the studies related to the sexual differentiation focused on the gonads. However, in fish, sexual plasticity is also reflected in the brain [Baroiller and D'Cotta, 2016; Lin et al., 2016; Chi et al., 2017], and therefore an involvement of the brain, or for that matter of other extragonadal tissues, in sex differentiation cannot be ruled out a priori. Moreover, the possibility of extragonadal involvement in ESD does not imply only the direct, top-down control of the processes leading to gonadal sex differentiation but could simply mean the transduction of environmental information [Gemmell et al., 2019; Hattori et al., 2020]. Likewise, in a broad sense, it does not even have to be limited to ESD [Blázquez and Somoza, 2010; Hattori et al., 2020]. Thus, it could easily apply to GSD if sexual differentiation in these species is found to start elsewhere than the gonads. Resolving these issues has been a cornerstone of our research.

The first attempts to probe the participation of the hypothalamic-pituitary-gonadal (HPG) axis in the process of gonadal sex determination of atheriniform fishes were conducted in O. bonariensis reared at feminizing, sexually-neutral, and masculinizing temperatures [Miranda et al., 2001, 2003]. The results of those studies revealed that the number of immunoreactive Gnrh expressing neurons in the preoptic area (Gnrh1 neurons) peaked during the CPSD for all 3 temperatures and that this was correlated with the number of Fsh (follicle-stimulating hormone) immunoreactive cells in the pituitary gland [Miranda et al., 2001, 2003]. Likewise, the abundance of $f \operatorname{sh} \beta$ and $\operatorname{lh} \beta$ ( $\beta$ subunits) in individual fish at a sexually neutral temperature showed an increase in both messengers in ap-

Sex Determination in Atheriniform Fishes proximately half of the fish sampled during the temperature sensitive period before the appearance of the first morphological signs of gonadal sex differentiation [Shinoda et al., 2010]. Taken together, these data constitute evidence that the HPG axis is active during the temperature sensitive period and could be implicated in the TSD of $O$. bonariensis, however, they did not constitute a clear cause-consequence proof of involvement. Recent results for Gnrh3-null zebrafish generated by CRISPR/Cas9 showed a male-biased sex ratio, indicating that Gnrh3 may be a key player in early sexual differentiation and reinforcing the importance of the brain in this process [Feng et al., 2020]. In view of these results, the role of Gnrh3 in species with ESD such as Atheriniformes must be reanalyzed. Another player that could be important for brain sex differentiation and must be considered is brain aromatase. Fish are peculiar because they have 2 aromatase genes: cyp19a1a, commonly known as gonadal aromatase, and cyp19a1b, known as brain aromatase [Tchoudakova and Callard, 1998]. Both genes are expressed in the gonads as well as in the brain but at different levels, and the relative abundance of transcripts in these tissues is the basis for their naming [Diotel et al., 2010]. Also, aromatase activity in fish brains is higher than in other vertebrate groups [Diotel et al., 2010]. It has also been demonstrated that Cyp19a1b is involved in the process of neurogenesis in the brain of adult $O$. bonariensis [StroblMazzulla et al., 2010], and this seems to be the case for other species as well [Diotel et al., 2013]. Surprisingly, cyp19a1b expression during early development was higher in the heads of $O$. bonariensis larvae reared at a masculinizing temperature than at a feminizing temperature [Strobl-Mazzulla et al., 2008]. Although apparently paradoxical, since aromatase is responsible for the conversion of androgens to estrogens, this observation in O. bonariensis has recently received support from a study that implicated Cyp19a1b in the process of brain masculinization in zebrafish [Lee et al., 2018]. More importantly, the expression of $c y p 19 a 1 b$ in the head preceded the expression of cyp19ala in the trunk of O. bonariensis before the first signs of gonadal differentiation at all temperatures [Karube et al., 2007; Strobl-Mazzulla et al., 2008]. Thus, although preliminary, these results also suggest that brain differentiation occurs early in development, and probably before gonadal sex determination, and that an enzyme involved in neurogenesis (brain aromatase) participates in the modeling of sexual structures of the brain. While early research on the involvement of the HPG axis in ESD and GSD of atheriniforms was largely constrained by the absence of a molecular marker of genotypic sex, this 
shortcoming is now redressed by the availability of amhy and these issues should be revisited.

The discovery that cortisol is implicated in stress-induced masculinization in O. bonariensis [Hattori et al., 2009; García-Cruz et al., 2020] has raised obvious questions as to how environmental factors are perceived by the fish and more specifically on the possible involvement of extragonadal tissues such as the hypothalamic-pituitary-interrenal (HPI) axis. In mammals, the stress response starts at the paraventricular nucleus of the hypothalamus (PVN) whose neurons, ending at the median eminence, synthesize and release $\mathrm{CRH}$ (corticotropin releasing hormone) to the portal vessels [Wamsteeker $\mathrm{Cu}$ sulin et al., 2013], promoting the release of the adrenocorticotropic hormone (ACTH) from the pituitary that in turn releases cortisol from the adrenal gland [Muglia et al., 2000]. This system has been studied also in fish [Mommsen et al., 1999; Gorissen and Flik, 2016; Rousseau et al., 2021]. Thus, CRH-producing neurons are located at the preoptic nucleus and tuberal hypothalamus ending in close apposition to ACTH-producing cells that stimulate the release of cortisol by the interrenal cells [Flik et al., 2006]. In this context, a recent study showed for the first time that the biallelic mutation of both Crh receptors (Crhr1 and Crhr2) in genetically female medaka not only reduced cortisol levels but also blocked high temperature-induced masculinization [Castañeda-Cortés et al., 2019]. These results provide compelling evidence that the HPI axis plays a key role in linking external environmental stimuli with physiological responses and could be the long-sought transducers of environmental information in ESD species. However, many questions remain to be answered such as the regulatory processes involving this gene and how the HPI modulates other factors that direct gonadal sex determination and differentiation. Our group is currently performing similar studies that hopefully will provide a more complete picture of the processes involved for atheriniform species. In parallel, we are also examining the TRPV family of TRP (transient receptor potential) ion channels that have been tentatively linked with transduction of thermal information in an alligator species with TSD [Yatsu et al., 2015].

\section{Expression of TSD in Wild Populations}

Water temperatures around the globe are expected to increase due to global warming at a rate faster than organisms have experienced during their evolution and therefore could have serious negative impacts on the de- mographics of TSD fish species [Ospina-Álvarez and Piferrer, 2008; Strüssmann et al., 2010; Yamamoto et al., 2019]. Climate change on the other hand may provoke untimely and erratic changes in temperature that are uncoupled from other seasonal factors such as photoperiod and barometric pressure that usually entrain spawning seasons in temperate and subtropical fish species, leading animals to experience extreme temperatures to which they are not adapted to at critical developmental stages [Strüssmann et al., 2010]. Thus, from the viewpoint of the conservation of the aquatic ecosystem, it is important to assess the negative effects of global warming and climate change on sex determination of wild fish populations (such as extremely biased sex ratios) and develop ways to mitigate them [Wedekind, 2017; Geffroy and Wedekind, 2020]. Interestingly, for species that can be artificially propagated and released to supplement declining natural populations, TSD provides a tool to counter the very problem it causes. Thus, the sex ratios of propagated fish could be designed to match the deficiency of a particular phenotypic or genotypic sex in wild populations. Of equal importance, highly thermosensitive species such as the atheriniforms might constitute early biological indicators of the effects of global warming and climate change on the ecosystem and on fish populations in general. The paucity of information on TSD in natural fish populations contrasts to the number of species in which it has been reported based on laboratory experiments [e.g., over 60 species; Baroiller et al., 2009; Baroiller and D'Cotta, 2016]. Field studies are constrained in part by the limited power of analysis based only on phenotypic sex ratios and specially by the difficulty in proving a causal relationship between unbalanced sex ratios and water temperature due to the complex interaction of environmental factors in nature. The discovery and characterization of amhy in several atheriniforms, as mentioned above, now allows us to determine the genotypic sex of each individual and spot genotypic/phenotypic sex mismatches (sex reversals) among wild fish with high resolution. Another tool that has recently become instrumental in field studies of TSD in fish is otolith increment and microchemical analysis [Strüssmann et al., 2003, 2010; Pringle and Baumann, 2019; Miyoshi et al., 2020]. Otoliths are calcified structures located in the inner ears of fish that are responsible primarily for the perception of gravity, balance, and movement. They grow by accretion of layers (increments) starting from a nucleus present at birth, and the chemical composition of each layer is affected by the physicochemical characteristics of the surrounding environment, making
86

Sex Dev 2021;15:80-92

DOI: $10.1159 / 000515191$
Strüssmann/Yamamoto/Hattori/ Fernandino/Somoza 
it possible to determine the birth date (hence the age) and even reconstruct the environmental history of individual fish [Strüssmann et al., 2020]. The combination of molecular and otolith-based tools dramatically increases the analytical resolution to tackle environmental influences on sex determination compared to what can be obtained solely from the analysis of phenotypic sex ratios.

Our group has been conducting field surveys of TSD in natural atheriniform populations in Japan and Argentina. The first field studies were conducted in an invasive population of $O$. bonariensis naturally established in the Lake Kasumigaura (Ibaraki, Japan). A 10-year survey of the phenotypic sex ratios of young-of-the-year in this lake revealed highly variable, skewed sex ratios including up to an excess of $80 \%$ males or females from year to year [Strüssmann et al., 2010]. Interestingly, years with an excess of males and females coincided with those having atypically high and low temperatures during the presumed spawning season, respectively, and drastic population declines were observed each time 2 consecutive years had highly skewed sex ratios for the same sex. Stored specimens from the 2001 year class of this population were re-screened recently using the amhy marker, revealing individuals with both types of genotype/phenotype mismatch (XX-male and XY-female) [Yamamoto et al., 2014]. We also noted an excess of $a m h y^{-}$(XX genotype) fish which could be an indication of the presence of sex-reversed XX-males in previous (adult) year classes. This once dominating population in the lake is now extinct even though it has never been subjected to commercial exploitation or eradication efforts. The presence of the reciprocal sex reversals in Lake Kasumigaura prompted an examination of the viability of thermally sex-reversed fish [Hattori et al., 2018]. The results showed not only that both were fertile but also that XY females could mate with normal XY males and yield YY offspring. Further examination revealed that YY fish would develop as males even at otherwise feminizing temperatures, probably because the 2 amhy copies offset the influence of temperature, and more importantly, that YY males were viable and fertile. A qPCR method to distinguish XY and YY genotypes has been developed for this species [Hattori et al., 2018] and is now being used together with otolith analysis and traditional sex ratio analysis to periodically survey $O$. bonariensis in its natural habitat in the Pampasic lakes in Argentina. Remarkably, YY males have been found in one of these lakes, the Chascomús Lake, together with sex-reversed XX males and XY females [Hattori et al., 2018; Y. Yamamoto et al., unpubl. observations].

Sex Determination in Atheriniform Fishes
Another species for which we have identified the amhy gene and are now able to conduct field surveys of sex reversal is $H$. tsurugae [Bej et al., 2017; Miyoshi et al., 2020]. This species is a marine atherinid from coastal environments of Japan and South Korea. Examination of the phenotypic and genotypic sex of juveniles from 3 consecutive year classes (2014-2016) in Tokyo Bay revealed that the proportion of phenotypic males increased year to year up to $80 \%$ in the last year, and that this trend was strongly associated with increases and decreases in the frequencies of XX males and XY/ YY females, respectively [Miyoshi et al., 2020]. It is noteworthy that approximately half of the XX individuals from the 2016 year class were phenotypic males. The young of $H$. tsurugae reside and grow up in small coves near the spawning grounds for several months after hatching [Mori et al., 1988]. To clarify the causes for the high rates of phenotypic males and XX male reversals in this population, we used otolith increment analysis to ascertain individual birth dates for each year class and assembled the results in relation to local water temperature records. The results showed that the period of birth of this population was delayed by about 1 month per year between 2014 and 2016, causing larvae to experience higher temperatures during the presumptive period of sex determination from year to year. These results for wild fish essentially corroborated the results of rearing experiments that showed feminization and masculinization in the same range of low and high temperatures, respectively [Miyoshi et al., 2020]. Otolith analysis has been employed also by Pringle and Baumann [2019] to estimate birth dates and reconstruct the growth trajectories of young-of-the year M. menidia in an attempt to field-test the assumption of early birth of females compared to males resulting from TSD (see previous explanation on the discovery of TSD in fish). The study indeed demonstrated that females are larger than males on average, but contrary to the initial expectations, this was mostly attributed to sex-specific growth differences and not due to the earlier birth of females. The results of that study suggest that factors like differential growth, predation, selective migration, and selective mortality could also shape the sex ratios of wild $M$. menidia populations and confound the expression of TSD in the wild. This case provides a painful reminder of the complexity of environmental factors shaping the sex ratios in wild populations and how difficult it would be to correctly predict the effects of global warming and climate change on species with ESD/TSD. 
Fig. 2. Overview of the current knowledge on the processes involved in testicular and ovarian differentiation in Atheriniformes. Information was drawn chiefly from studies on the pejerrey $O$. bonariensis but also includes inferences for other species. Environmental cues are likely perceived by different organs and canalized to the brain which in turn send signals to the pituitary. From the pituitary, signals are sent to the gonads directly or indirectly via the interrenal. Other pathways such as a direct effect of temperature on the gonads are conceivable from studies in other species but have not yet been verified in Atheriniformes. Genes upregulated at the transcriptional level during the sex determination period are shown for the brain and gonads. Question marks indicate tissues whose participation in gonadal sex determination is likely but still needs further verification. ESD, environmental sex determination; GSD, genotypic sex determination.

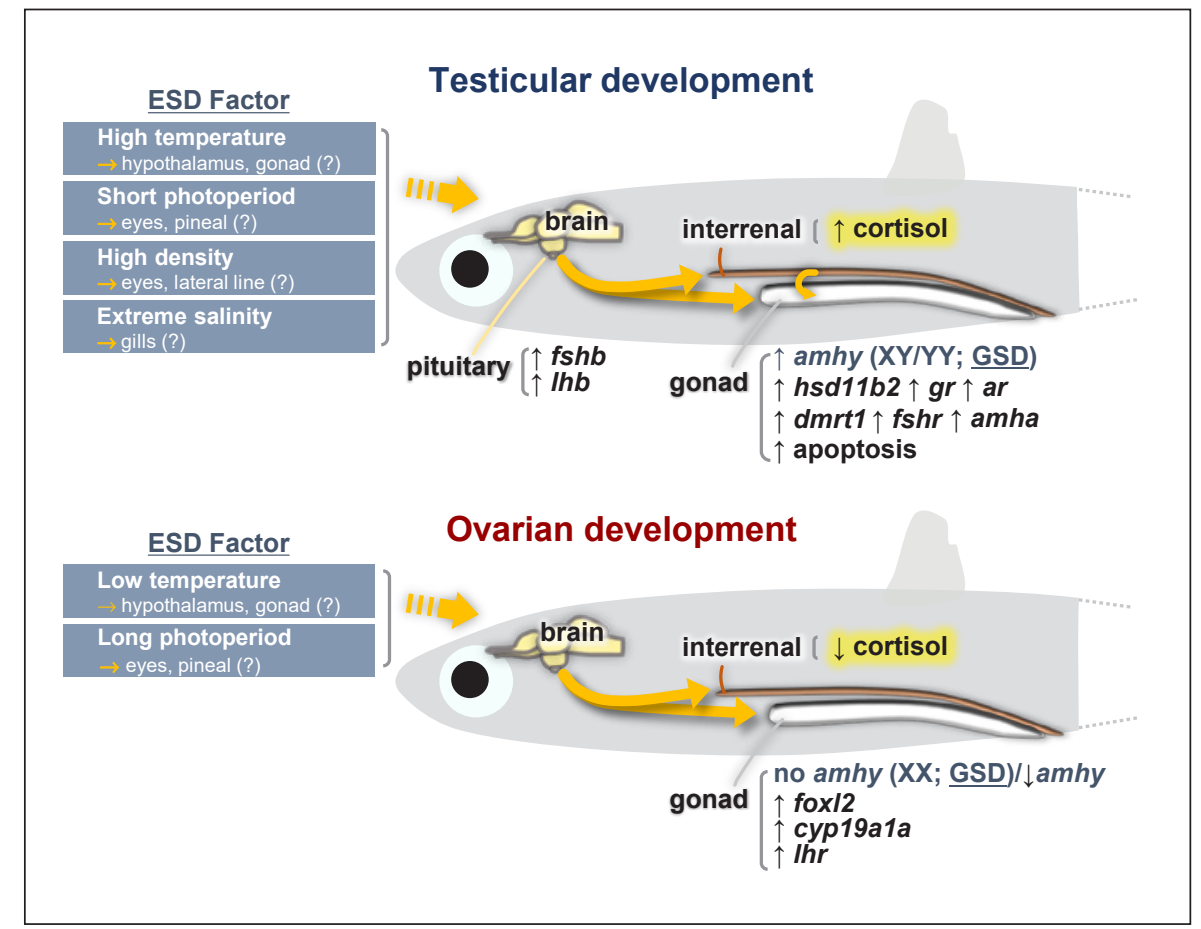

\section{Ongoing Research and Perspectives}

As described in the previous sections, laboratory and field research on sex determination in atheriniform species conducted mainly in the last decades has already yielded a wealth of novel findings, starting from the very discovery of environmental sex determination in fish that extends those obtained with the traditional experimental models (e.g., medaka: Beloniformes, zebrafish: Cypriniformes, cichlids: Cichliformes, and salmonids: Salmoniformes; see other articles in this special issue). The discovery of amhy showed for the first time that nontranscription factors can evolve as master sex-determining genes, and it is now known that this gene has been co-opted for genetic sex (testis) determination by teleosts from other orders and even in non-teleost taxa [Hattori et al., 2012, 2013, 2019; Cortez et al., 2014; Li et al., 2015; Pan et al., 2019]. The highly divergent sequence of amhy in relation to the autosomal amha in both Old and New World silversides, especially in the presumptive promoter regions, together with the widespread occurrence of TSD in this group, suggests that amhy (GSD) has coexisted with TSD/ESD for a considerable long time. This raises the obvious questions of what the fitness advantages of either system are and how both could have persisted/coexisted. One hypothesis that might be explored is that both complement each other, for example, by permitting the exploration of a (hitherto unknown) adaptive advantage of TSD in the short term while GSD (more specifically, the sex-reversed XX males and XY females) provides a mechanism to restore the balance of sex chromosomes in the long term. Obviously, to be effective, this requires the existence of both feminization (of XY) at low temperatures and masculinization (of XX) at high temperatures, which is indeed the case in Atheriniformes. As discussed above, it is tempting to conclude on the ancestrality of ESD and the role of stress and cortisol in this mode of sex determination among atheriniforms, as recently suggested across a broad range of taxa [Straková et al., 2020]. Further studies on the evolutionary mechanisms and adaptive significance of TSD/ESD among atheriniforms would greatly benefit from the phylogenetic analysis of the patterns of TSD/ESD in relation to longevity as performed for other taxa [Pokorná and Kratochvíl, 2016; Sabath et al., 2016] and probably also reproductive modes (semelparity vs. iteroparity, monogamy vs. polygamy, etc.) [Geffroy and Douhard, 2019] and the existence or not of reciprocal sex reversal (i.e., feminization of XY and masculinization of XX). Given the relatively fast transition from ESD (TSD) to GSD empirically demonstrated in the Menidia model [Conover et al., 1992] and the apparent lack of TSD in A. affinis
Strüssmann/Yamamoto/Hattori/ Fernandino/Somoza 
[Baumann et al., 2012], the existence or not of past thermal bottlenecks must be necessarily considered.

For a long time, the absence of a reliable molecular marker of genetic sex has made it impossible to discriminate between genetic and environmental effects during early development. Still, the results of studies on extragonadal factors related to sex determination performed before the discovery of amhy strongly suggested that the brain is a transducer of environmental information during TSD/ESD using either the HPG and/or HPI axes as the link. In fact it is possible that sex determination in atheriniforms starts in the brain and is then imprinted onto the gonads (Fig. 2). Ongoing research using amhy is expected to confirm and elaborate those findings. Other exciting areas that are being explored further with the help of the amhy marker are sexual dimorphic stress sensitiveness, the female default hypothesis and associated molecular and histological gradients of gonadal sex differentiation, and the regulatory processes of sex differentiation genes during the CPSD. The recent publication of sequences for the entire genome of the pejerrey, although in a partial form (GenBank assembly accession GCA_014825785.1), would greatly assist us in tackling these challenging issues. Likewise, genotypic/phenotypic sex mismatches can be easily identified in wild individuals using amhy, and this means that local atheriniform populations with TSD/ESD could be developed as earlywarning bioindicator species of the effects of climatic anomalies and other forms of environmental stress on fish resources.

\section{Conflict of Interest Statement}

The authors have no conflicts of interest to declare.

\section{Funding Sources}

This work was supported by grants from the Japan Society for the Promotion of Science (JSPS KAKENHI) to Y.Y. (15K18728, 15KK0277 and 19H03048) and C.A.S. (19H01162), the Fundação de Amparo à Pesquisa do Estado de São Paulo (FAPESP) to R.S.H. (2013/17612-9), and the Agencia Nacional de Promoción Científica y Tecnológica (ANPCyT) to J.I.F. (PICT, 2018-1875) and G.M.S. (PICT, 2015-2783).

\section{Author Contributions}

C.A.S. drafted the introduction, the 2 nd and 6 th sections, and overviewed the entire manuscript, R.S.H. drafted the 3 rd section, G.M.S. and J.F. drafted the 4th section, and Y.Y. drafted the 5th section. All authors reviewed the final version of the manuscript.

\section{References}

Baroiller JF, D'Cotta H. The reversible sex of gonochoristic fish: Insights and consequences. Sex Dev. 2016;10(5-6):242-66.

Baroiller JF, D'Cotta H, Saillant E. Environmental effects on fish sex determination and differentiation. Sex Dev. 2009;3(2-3):118-35.

Baumann H, Rosales Casián JA, Conover DO. Contrasting latitudinal variations in vertebral number and sex determination in $\mathrm{Pa}$ cific versus Atlantic silverside fishes. Copeia. 2012;2012(2):341-50.2012

Blázquez M, Somoza GM. Fish with thermolabile sex determination (TSD) as models to study brain sex differentiation. Gen Comp Endocrinol. 2010;166(3):470-7.

Bej DK, Miyoshi K, Hattori RS, Strüssmann CA, Yamamoto Y. A duplicated, truncated amh gene is involved in male sex determination in an Old World silverside. G3. 2017;7(8): 2489-95.

Bull JJ, Bulmer MG. Longevity enhances selection of environmental sex determination. Heredity. 1989;63(Pt 3):315-20.

Brown EE, Baumann H, Conover DO. Temperature and photoperiod effects on sex determination in a fish. J Exp Mar Biol Ecol. 2014; 461:39-43.
Campanella D, Hughes LC, Unmack PJ, Bloom DD, Piller KR, Ortí G. Multi-locus fossilcalibrated phylogeny of Atheriniformes (Teleostei, Ovalentaria). Mol Phylogenet Evol. 2015;86:8-23.

Castañeda-Cortés DC, Arias Padilla LF, Langlois VS, Somoza GM, Fernandino JI. The central nervous system acts as a transducer of stress-induced masculinization through corticotropin-releasing hormone B. Development. 2019;146: dev172866.

Castañeda-Cortés DC, Zhang J, Boan AF, Langlois VS, Fernandino JI. High temperature stress response is not sexually dimorphic at the whole-body level and is dependent on androgens to induce sex reversal. Gen Comp Endocrinol. 2020;299:113605.

Chi W, Gao Y, Hu Q, Guo W, Li D. Genomewide analysis of brain and gonad transcripts reveals changes of key sex reversal-related genes expression and signaling pathways in three stages of Monopterus albus. PloS One. 2017;12(3):e0173974.

Conover DO. Adaptive significance of temperature-dependent sex determination in a fish. Am Nat. 1984;123(3):297-313.
Conover DO. Seasonality and the scheduling of life history at different latitudes. J Fish Biology. 1992;41(sb):161-78.

Conover DO. Temperature-dependent sex determination in fishes. In: Vanlenzuela $\mathrm{N}$, Lance V (eds). Temperature-Dependent Sex Determination in Vertebrates. Washington DC: Smithsonian Books; 2004. p. 11-20.

Conover DO, Fleisher MH. Temperature-sensitive period of sex determination in the Atlantic silverside, Menidia menidia. Can J Fish Aquat Sci. 1986;43(3):514-20.

Conover DO, Heins SW. Adaptive variation in environmental and genetic sex determination in a fish. Nature. 1987a;326(6112):496-8.

Conover DO, Heins SW. The environmental and genetic components of sex ratio in $\mathrm{Me}$ nidia menidia (Pisces: Atherinidae). Copeia. 1987b; 1987(3):732-43.

Conover DO, Kynard BE. Environmental sex determination: interaction of temperature and genotype in a fish. Science. 1981;213(4507):577-9.

Conover DO, Van Voorhees DA, Ehtisham A. Sex ratio selection and the evolution of environmental sex determination in laboratory populations of Menidia menidia. Evolution. 1992;46(6):1722-30. 
Corona-Herrera GA, Tello-Ballinas JA, Hattori RS, Martínez-Palacios CA, Strüssmann CA, Cárdenas-Reygadas RR, et al . Gonadal differentiation and temperature effects on sex determination in the freshwater pike silverside Chirostoma estor Jordan 1880. Environ Biol Fish. 2016;99(5):463-71.

Corona-Herrera GA, Arranz SE, Martínez-Palacios CA, Navarrete-Ramírez P, ToledoCuevas EM, Valdez-Alarcón JJ, et al. Experimental evidence of masculinization by continuous illumination in a temperature sex determination teleost (Atherinopsidae) model: is oxidative stress involved?. J Fish Biol. 2018;93(2):229-37.

Cortez D, Marin R, Toledo-Flores D, Froidevaux L, Liechti A, Waters PD, et al. Origins and functional evolution of $\mathrm{Y}$ chromosomes across mammals. Nature. 2014;508(7497): 488-93.

DeCourten BM, Brander SM. Combined effects of increased temperature and endocrine disrupting pollutants on sex determination, survival, and development across generations. Sci Rep. 2017;7(1):9310.

Diotel N, Le Page Y, Mouriec K, Tong SK, Pellegrini E, Vaillant C, et al. Aromatase in the brain of teleost fish: Expression, regulation and putative functions. Front Neuroendocrinol. 2010;31(2):172-92.

Diotel N, Vaillant C, Gabbero C, Mironov S, Fostier A, Gueguen MM, et al. Effects of estradiol in adult neurogenesis and brain repair in zebrafish. Horm Behav. 2013;63(2): 193-207.

Duffy TA, Picha ME, Won ET, Borski RJ, McElroy $\mathrm{AE}$, Conover $\mathrm{DO}$. Ontogenesis of gonadal aromatase gene expression in Atlantic silverside (Menidia menidia) populations with genetic and temperature-dependent sex determination. J Exp Zool A Ecol Genet Physiol. 2010;313(7):421-31.

Feng K, Cui X, Song Y, Tao B, Chen J, Wang J, et al. Gnrh3 regulates PGC proliferation and sex differentiation in developing zebrafish. Endocrinology. 2020;161(1):1-3.

Fernandino JI, Hattori RS, Kimura H, Strüssmann CA, Somoza GM. Expression profile and estrogenic regulation of anti-Müllerian hormone during gonadal development in pejerrey Odontesthes bonariensis, a teleost fish with strong temperature-dependent sex determination. Dev Dyn. 2008a;237(11): 3192-9.

Fernandino JI, Hattori RS, Shinoda T, Kimura $\mathrm{H}$, Strobl-Mazzulla PH, Strüssmann CA, et al. Dimorphic expression of dmrt1 and cyp19a1 (ovarian aromatase) during early gonadal development in pejerrey. Odontesthes bonariensis. Sex Dev. 2008b;2:316-24.

Fernandino JI, Popesku JT, Paul-Prasanth B, Xiong H, Hattori RS, Oura M, et al. Analysis of sexually dimorphic expression of genes at early gonadogenesis of pejerrey Odontesthes bonariensis using a heterologous $\mathrm{mi}$ croarray. Sex Dev. 2010;5(2):89-101.
Fernandino JI, Hattori RS, Kishii A, Strüssmann CA, Somoza GM. The cortisol and androgen pathways cross talk in high temperature-induced masculinization: The $11 \beta$-hydroxysteroid dehydrogenase as a key enzyme. Endocrinology. 2012;153:6003-11.

Fernandino JI, Hattori RS, Moreno Acosta OD, Strüssmann CA, Somoza GM. Environmental stress-induced testis differentiation: Androgen as a by-product of cortisol inactivation. Gen Comp Endocrinol. 2013;192:3644.

Flik G, Klaren PH, Van den Burg EH, Metz JR, Huising MO. CRF and stress in fish. Gen Comp Endocrinol. 2006;146(1):36-44.

García-Cruz EL, Yamamoto Y, Hattori RS, de Vasconcelos LM, LM, Strüssmann CA, et al. Crowding stress during the period of sex determination causes masculinization in pejerrey Odontesthes bonariensis, a fish with temperature-dependent sex determination. Comp Biochem Physiol A Mol Integr Physiol. 2020;245:110701.

Geffroy B, Douhard M. The adaptive sex in stressful environments. Trends Ecol Evol. 2019;34(7):628-40.

Geffroy B, Wedekind C. Effects of global warming on sex ratios in fishes. J Fish Biol. 2020; 97(3):596-606

Gemmell NJ, Todd EV, Goikoetxea A, OrtegaRecalde O, Hore TA. Natural sex change in fish. Curr Top Dev Biol. 2019;134:71-117.

Gorissen M, Flik G. The endocrinology of the stress response in fish: An adaptation-physiological view. In: Schreck CB, Tort L, Farrell AP, Brauner CJ (eds). Fish Physiology, Vol 35. New York: Elsevier; 2016. p. 75-111.

Hayashi Y, Kobira H, Yamaguchi T, Shiraishi E, Yazawa T, Hirai T, et al. High temperature causes masculinization of genetically female medaka by elevation of cortisol. Mol Reprod Dev. 2010;77(8):679-86.

Hattori RS, Fernandino JI, Kishii A, Kimura H, Kinno T, Oura M, et al. Cortisol-induced masculinization: Does thermal stress affect gonadal fate in pejerrey, a teleost fish with temperature-dependent sex determination? PLoS One. 2009;4(8):e6548.

Hattori RS, Oura M, Sakamoto T, Yokota M, Watanabe S, Strüssmann CA. Establishment of a strain inheriting a sex-linked SNP marker in Patagonian pejerrey (Odontesthes hatcheri), a species with both genotypic and temperature-dependent sex determination. Anim Genet. 2010;41(1):81-4.

Hattori RS, Murai Y, Oura M, Masuda S, Majhi SK, Sakamoto T, et al. A Y-linked anti-Müllerian hormone duplication takes over a critical role in sex determination. Proc Natl Acad Sci USA. 2012;109(8):2955-9.

Hattori RS, Tashiro S, Zhang Y, Kakuta N, Yokota M, Strüssmann CA, et al. Demonstration of viability and fertility and development of a molecular tool to identify YY supermales in a fish with both genotypic and environmental sex determination. Ecol Evol. 2018;8(15):7522-8.
Hattori RS, Somoza GM, Fernandino JI, Colautti DC, Miyoshi K, Gong Z, et al. The duplicated $Y$-specific amhy gene is conserved and linked to maleness in silversides of the genus Odontesthes. Genes. 2019;10(9):679.

Hattori RS, Castañeda-Cortés DC, Arias Padilla LF, Strobl-Mazzulla PH, Fernandino JI. Activation of stress response axis as a key process in environment-induced sex plasticity in fish. Cell Mol Life Sci. 2020;77(21):422336.

Ito LS, Yamashita M, Takashima F, Strüssmann CA. Dynamics and histological characteristics of gonadal sex differentiation in pejerrey (Odontesthes bonariensis) at feminizing and masculinizing temperatures. J Exp Zoolog Part A Comp Exp Biol. 2005;303(6):50414.

Janzen FJ, Phillips PC. Exploring the evolution of environmental sex determination, especially in reptiles. J Evol Biol. 2006;19(6): 1775-84.

Karube M, Fernandino JI, Strobl-Mazzulla P, Strüssmann CA, Yoshizaki G, Somoza GM, et al. Characterization and expression profile of the ovarian cytochrome P-450 aromatase (cyp19A1) gene during thermolabile sex determination in pejerrey, Odontesthes bonariensis. J Exp Zool A Ecol Genet Physiol. 2007;307(11):625-36.

Koshimizu E, Strüssmann CA, Okamoto N, Fukuda H, Sakamoto T. Construction of a genetic map and development of DNA markers linked to the sex determining locus in the Patagonian pejerrey (Odontesthes hatcheri). Mar Biotechnol. 2010;12:8-13.

Lagomarsino IV, Conover DO. Variation in environmental and genotypic sex-determining mechanisms across a latitudinal gradient in the fish, Menidia menidia. Evolution. 1993; 47(2):487-94.

Lee SLJ, Horsfield JA, Black MA, Rutherford K, Gemmell NJ. Identification of sex differences in zebrafish (Danio rerio) brains during early sexual differentiation and masculinization using $17 \alpha$-methyltestoterone. Biol Reprod. 2018;99(2):446-60.

Li M, Sun Y, Zhao J, Shi H, Zeng S, Ye K, et al. A tandem duplicate of anti-Müllerian hormone with a missense SNP on the Y chromosome is essential for male sex determination in Nile tilapia, Oreochromis niloticus. PLoS Genet. 2015;11(11):e1005678.

Lin CJ, Fan-Chiang YC, Dufour S, Chang CF. Activation of brain steroidogenesis and neurogenesis during the gonadal differentiation in protandrous black porgy, Acanthopagrus schlegelii. Dev Neurobiol. 2016;76(2):12136.

Mankiewicz JL, Godwin J, Holler BL, Turner PM, Murashige R, Shamey R, et al. Masculinizing effect of background color and cortisol in a flatfish with environmental sex-determination. Integr Comp Biol. 2013;53(4): 755-65.
90

Sex Dev 2021;15:80-92

DOI: $10.1159 / 000515191$
Strüssmann/Yamamoto/Hattori/

Fernandino/Somoza 
Middaugh DP, Hemmer MJ. Influence of environmental temperature on sex-ratios in the tidewater silverside, Menidia peninsulae (Pisces: Atherinidae). Copeia. 1987;1987(4): 958-64.1987

Miranda LA, Strobl-Mazzulla PH, Strüssmann CA, Parhar I, Somoza GM. Gonadotropinreleasing hormone neuronal development during the sensitive period of temperature sex determination in the pejerrey fish, Odontesthes bonariensis. Gen Comp Endocrinol. 2003;132(3):444-53.

Miranda LA, Strüssmann CA, Somoza GM. Immunocytochemical identification of $\mathrm{GtH} 1$ and $\mathrm{GtH} 2$ cells during the temperature-sensitive period for sex determination in pejerrey, Odontesthes bonariensis. Gen Comp Endocrinol. 2001;124(1):45-52.

Miyoshi K, Hattori RS, Strüssmann CA, Yokota $\mathrm{M}$, Yamamoto Y. Phenotypic/genotypic sex mismatches and temperature-dependent sex determination in a wild population of an Old World atherinid, the cobaltcap silverside Hypoatherina tsurugae. Mol Ecol. 2020 29(13):2349-58.

Mommsen TP, Vijayan MM, Moon TW. Cortisol in teleosts: dynamics, mechanisms of action, and metabolic regulation. Rev Fish Bio Fish. 1999;9(3):211-68

Moreno-Mendoza N, Harley VR, MerchantLarios H. Temperature regulates SOX9 expression in cultured gonads of Lepidochelys olivacea, a species with temperature sex determination. Dev Biol. 2001;229(2):319-26.

Mori K, Kimura K, Tsukamoto Y, Kawano Y, Yoshida M. Growth of the atherinid Hypoatherina tsurugae in Ago Bay, Central Japan. Suisanzoshoku. 1988;36:87-90.

Muglia LJ, Bethin KE, Jacobson L, Vogt SK, Majzoub JA. Pituitary-adrenal axis regulation in CRH-deficient mice. Endocr Res. 2000 26(4):1057-66.

Nelson JS, Grande TC, Wilson MVH. Fishes of the World, ed 5. New York: John Wiley \& Sons; 2016.

Nakamoto M, Shibata Y, Ohno K, Usami T, Kamei $Y$, Taniguchi $Y$, et al. Ovarian aromatase loss-of-function mutant medaka undergo ovary degeneration and partial female-tomale sex reversal after puberty. Mol Cell Endocrinol. 2018:460:104-22.

Ospina-Álvarez N, Piferrer F. Temperature-dependent sex determination in fish revisited Prevalence, a single sex ratio response pattern, and possible effects of climate change. PLoS One. 2008;3(7):e2837.

Pan Q, Feron R, Yano A, Guyomard R, Jouanno $\mathrm{E}$, Vigouroux $\mathrm{E}$, et al. Identification of the master sex determining gene in Northern pike (Esox lucius) reveals restricted sex chromosome differentiation. PLoS Genet. 2019;15(8):e1008013.

Pieau C, Dorizzi M. Oestrogens and temperature-dependent sex determination in reptiles: all is in the gonads. J Endocrinol. 2004 181(3):367-77.
Pokorná MJ, Kratochvíl L. What was the ancestral sex-determining mechanism in amniote vertebrates?. Biol Rev. 2016;91(1):1-12.

Pringle J, Baumann H. Otolith-based growth reconstructions in young-of-year Atlantic silversides Menidia menidia and their implications for sex-selective survival. Mar Ecol Prog Ser. 2019;632:193-204.

Ribas L, Liew WC, Díaz N, Sreenivasan R, Orbán L, Piferrer F. Heat-induced masculinization in domesticated zebrafish is familyspecific and yields a set of different gonadal transcriptomes. Proc Natl Acad Sci USA. 2017;114(6):E941-50

Rousseau K, Prunet P, Dufour S. Special features of neuroendocrine interactions between stress and reproduction in teleosts. Gen Comp Endocrinol. 2021;300:113634.

Sarida M, Hattori RS, Zhang Y, Yamamoto Y, Strüssmann CA. Spatiotemporal correlations between amh and cyp19ala transcript expression and apoptosis during gonadal sex differentiation of pejerrey, Odontesthes bonariensis. Sex Dev. 2019;13(2):99-108.

Sabath N, Itescu Y, Feldman A, Meiri S, Mayrose I, Valenzuela N. Sex determination, longevity, and the birth and death of reptilian species. Ecol Evol. 2016;6(15): 5207-20.

Shinoda T, Miranda LA, Okuma K, Hattori RS, Fernandino JI, Yoshizaki G, et al. Molecular cloning and expression analysis of Fshr and Lhr in relation to Fshb and Lhb subunits during the period of temperature-dependent sex determination in pejerrey Odontesthes bonariensis. Mol Reprod Dev. 2010;77(6): 521-32.

Straková B, Rovatsos M, Kubička L, Kratochvíl L. Evolution of sex determination in amniotes: Did stress and sequential hermaphroditism produce environmental determination? BioEssays. 2020;2020(42):2000050.

Strobl-Mazzulla PH, Lethimonier C, Gueguen MM, Karube M, Fernandino JI, Yoshizaki G et al. Brain aromatase (Cyp19A2) and estrogen receptors, in larvae and adult pejerrey fish Odontesthes bonariensis: Neuroanatomical and functional relations. Gen Comp Endocrinol. 2008;158(2):191-201.

Strobl-Mazzulla PH, Nuñez A, Pellegrini E, Gueguen MM, Kah O, Somoza GM. Progenitor radial cells and neurogenesis in pejerrey fish forebrain. Brain Behav Evol. 2010;76(1): 20-31.

Strüssmann CA, Patiño R Strüssmann CA, Patiño R. Temperature manipulation of sex differentiation in fish. In: Goetz FW, Thomas $P$ (eds). Proceedings of the Fifth International Symposium on the Reproductive Physiology of Fish. Austin: FishSymp95; 1995. p. 153-7.

Strüssmann CA, Patiño R. Sex determination, environmental. In: Knobil E, Neill JD (eds) Encyclopedia of Reproduction, Vol. 4. San Diego: Academic Press; 1999. p. 402-9.
Strüssmann CA, Ito LS. Where does gonadal sex differentiation begin? Gradient of histological sex differentiation in the gonads of pejerrey, Odontesthes bonariensis (Pisces, Atherinidae). J Morphol. 2005;265(2):190-

Strüssmann C, Moriyama S, Hanke EF, Calsina Cota JC, Takashima F. Evidence of thermolabile sex determination in pejerrey. J Fish Biol. 1996a;48(4):643-51.

Strüssmann CA, Calsina Cota JC, Phonlor G, Higuchi $\mathrm{H}$, Takashima F. Temperature effects on sex differentiation of two South American atherinids, Odontesthes argentinensis and Patagonina hatcheri. Environ Biol Fish. 1996b;47:143-54.

Strüssmann CA, Takashima F, Toda K. Sex differentiation and hormonal feminization in pejerrey Odontesthes bonariensis. Aquaculture. 1996c;139(1-2):31-45.

Strüssmann CA, Saito T, Usui M, Yamada $\mathrm{H}$, Takashima F. Thermal thresholds and critical period of thermolabile sex determination in two atherinid fishes, Odontesthes bonariensis andPatagonina hatcheri. J Exp Zool. 1997;278(3):167-77.

Strüssmann CA, Oikawa T, Otake T, Kasuga S. Potential use of otolith microchemistry for field studies of temperature-dependent sex determination and gonadal degeneration in fish. Fish Physiol Biochem. 2003;28(1-4) 129-30.

Strüssmann CA, Conover DO, Somoza GM, Miranda LA. Implications of climate change for the reproductive capacity and survival of New World silversides (family Atherinopsidae). J Fish Biol. 2010;77(8):1818-34.

Strüssmann CA, Miyoshi K, Mitsui S. A novel, efficient method for otolith specimen preparation using UV-cured resins. North Am J Fish Manage. 2020;40(5):1187-94.

Sun L, Teng J, Zhao Y, Li N, Wang H, Ji X. Gonad transcriptome analysis of high-temperature-treated females and high-temperature-induced sex-reversed neomales in Nile Tilapia. Ijms. 2018;19(3):689.

Tchoudakova A, Callard GV. Identification of multiple CYP19 genes encoding different cytochrome P450 aromatase isozymes in brain and ovary. Endocrinology. 1998; 139(4):2179-89.

Wamsteeker Cusulin JI, Füzesi T, Watts AG, Bains JS. Characterization of corticotropinreleasing hormone neurons in the paraventricular nucleus of the hypothalamus of Crh-IRES-Cre mutant mice. PLoS One. 2013;8(5):e64943.

Wang Q, Liu K, Feng B, Zhang Z, Wang R, Tang $\mathrm{L}$, et al. Transcriptome of gonads from high temperature induced sex reversal during sex determination and differentiation in Chinese tongue sole, Cynoglossus semilaevis. Front Genet. 2019;10:1128.

Warr N, Greenfield A. The molecular and cellular basis of gonadal sex reversal in mice and humans. Wiley Interdiscip Rev Dev Biol. 2012;1(4):559-77. 
Wedekind C. Demographic and genetic consequences of disturbed sex determination. Philos Trans R Soc Lond B Biol Sci. 2017; 372(1729):20160326.

Yamaguchi T, Yoshinaga N, Yazawa T, Gen K, Kitano T. Cortisol is involved in temperature-dependent sex determination in the Japanese flounder. Endocrinology. 2010;151(8):3900-8.

Yamamoto Y, Hattori RS, Kitahara A, Kimura H, Yamashita M, Strüssmann CA. Thermal and endocrine regulation of gonadal apoptosis during sex differentiation in pejerrey Odontesthes bonariensis. Sex Dev. 2013; 7(6):316-24.
Yamamoto Y, Zhang Y, Sarida M, Hattori RS, Strüssmann CA. Coexistence of genotypic and temperature-dependent sex determination in pejerrey Odontesthes bonariensis. PLoS One. 2014;9(7):e102574.

Yamamoto Y, Hattori RS, Patiño R, Strüssmann CA. Environmental regulation of sex determination in fishes: Insights from Atheriniformes. Curr Top Dev Biol. 2019;134:49-69.

Yatsu R, Miyagawa S, Kohno S, Saito S, Lowers $\mathrm{RH}$, Ogino $\mathrm{Y}$, et al. TRPV4 associates environmental temperature and sex determination in the American alligator. Sci Rep. 2015; 5:18581.
Yin Y, Tang H, Liu Y, Chen Y, Li G, Liu X, et al. Targeted disruption of aromatase reveals dual functions of cyp19a1a during sex differentiation in zebrafish. Endocrinology. 2017;158(9):3030-41.

Zhang Y, Hattori RS, Sarida M, García EL, Strüssmann CA, Yamamoto Y. Expression profiles of amhy and major sex-related genes during gonadal sex differentiation and their relation with genotypic and temperature-dependent sex determination in pejerrey Odontesthes bonariensis. Gen Comp Endocrinol. 2018;265:196-201. 